\title{
Analisis Pengukuran Kinerja Koperasi Tani Duta Kartika Kencana dengan Pendekatan Balanced Scorecard
}

\author{
I Gede Candra Kusuma1 \\ Fakultas Ekonomi dan Bisnis \\ Universitas Udayana, Indonesia
}

\author{
I Ketut Suryanawa ${ }^{2}$ \\ Fakultas Ekonomi dan Bisnis \\ Universitas Udayana, Indonesia
}

Surel : candrakusuma19302@gmail.com

\section{ABSTRAK}

Penelitian balanced scorecard didasari berbagai teori dan latar belakang tempat yang berbeda. Penelitian dilakukan pada Koperasi Tani Duta Kartika Kencana yang masih melakukan pengukuran secara tradisional yaitu hanya melihat dari aspek keuangan saja sehingga tidak sesuai dengan target yang ingin dicapai oleh koperasi. Pengukuran kinerja berbasis balanced scorecard merupakan tujuan dari penelitian ini khusunya pada Koperasi Tani Duta Kartika Kencana. Jenis penelitian ini adalah studi kasus. Analisis deskriptif dan komparatif menjadi teknik analisis data. Keuangan, pelanggan, proses internal bisnis serta pembelajaran dan pertumbuhan menjadi perspektif balanced scorecard. Berdasarkan hasil analisis pengukuran yang telah dilakukan memperlihatkan bahwa kinerja Koperasi Tani Duta Kartika Kencana secara keseluruhan sudah cukup baik, hal tersebut ditunjukan dari nilai skor yang dihasilkan masingmasing perspektif.

Kata Kunci: $\quad$ Balanced Scorecard; Koperasi; Penilaian Kinerja.

\section{Analysis of the Performance Measurement of Duta Kartika Kencana Farmers Cooperative with a Balanced Scorecard Approach}

\begin{abstract}
Balanced scorecard research is based on various theories and backgrounds in different places. The research was conducted at the Duta Kartika Kencana Farmer's Cooperative, which still performs traditional measurements, which only looks at the financial aspect so that it is not in accordance with the targets to be achieved by the cooperative. Performance measurement based on the balanced scorecard is the goal of this research, especially at the Duta Kartika Kencana Farmers Cooperative. This type of research is a case study. Descriptive and comparative analysis are data analysis techniques. Finance, customers, internal business processes as well as learning and growth into a balanced scorecardperspective. Based on the results of the measurement analysis that has been carried out, it shows that the performance of the Duta Kartika Kencana Farmers Cooperative as a whole is quite good, this is shown from the scores generated by each perspective.
\end{abstract}

Keywords: Balanced Scorecard; Cooperative; Performance Appraisal.

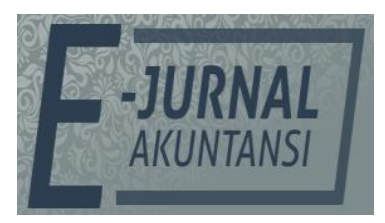

e-ISSN 2302-8556

Vol. 31 No. 11

Denpasar, November 2021

Hal. 2853-2866

DOI:

10.24843/EJA.2021.v31.i11.p14

PENGUTIPAN:

Kusuma, I. G. C., \& Suryanawa,

I. K. (2021). Analisis

Pengukuran Kinerja Koperasi Tani Duta Kartika Kencana dengan Pendekatan Balanced Scorecard. E-Jurnal Akuntansi, 31(11), 2853-2866

RIWAYAT ARTIKEL: Artikel Masuk: 12 Mei 2021 Artikel Diterima: 29 Juli 2021

Artikel dapat diakses: https:/ / ojs.unud.ac.id/index.php/Akuntansi/index 


\section{PENDAHULUAN}

Peran ekonomi sangat vital bagi pergerakan ekonomi dalam kegiatan usaha yang ada di Indonesia Indranatha \& Suryanawa, (2013). Setiap pelaku ekonomi yang ada di Indonesia selalu berupaya membangun perekonomian yang kemudian dapat membantu meningkatkan kesejahteraan rakyat Indonesia. Pergerakan ekonomi nasional bertumpu pada tiga pilar, yaitu Badan Usaha Milik Negara (BUMN), swasta dan koperasi yang senantiasa melakukan segala macam upaya dalam memberikan bantuan serta fasiltas kepada masyarakat dan Usaha Mikro, Kecil dan Menengah (UMKM) Ekmekçi, (2014).

Sejalan dengan UU No.20 Tahun 2008 yang dimana tentang sektor UMKM supaya mampu berkembang menjadi tumbuh dan mandiri perlu adanya pemberdayaan sebagai bagian ekonomi rakyat yang utuh. Akhirnya terciptanya kompetisi yang sehat dari penyaluran dana dari masing-masing badan usaha untuk membantu sektor UMKM maupun masyarakat. Kinerja perusahaan merupakan sebuah hasil dari kegiatan manajemen sebuah perusahaan yang mengacu pada standar yang ditetapkan dalam periodetertentu Fatima \& Elbanna, (2020). Maka dari itu, makna penilaian kinerja perusahaan (companies performance assessment) adalah suatu proses atau sistem penilaian mengenai pelaksanaan kemampuan kerja suatu perusahaan atau organisasi berdasarkan standar tertentu Sudibyo, (1997).

Pengukuran kinerja merupakan faktor penting dalam sebuah perusahaan. Pengukuran ini dapat digunakan untuk menilai tingkat keberhasilan suatu perusahaan juga dapat digunakan sebagai dasar penyusunan imbalan dalam perusahaan Kádárová, Durkáčová, \& Kalafusová, (2014). Selama ini beberapa perusahaan atau organisasi masih melakukan pengukuran kinerja secara tradisional yang hanya menilai tingkat keberhasilan kinerja suatu perusahaan dari sisi keuangan saja. Pengukuran kinerja yang menitik beratkan pada aspek keuangan hanya akan menghasilkan laba maksimal dalam jangka pendek. Sebaiknya, dalam pengukuran kinerja suatu perusahaan haruslah seimbang baik pengukuran kinerja dari sisi keuangan maupun non keuangan. Karena jika hanya melihat dari sisi keuangan atau finansialnya saja belum dapat memberikan gambaran yang riil mengenai keadaan perusahaan, justru hal ini akan memberikan informasi atau hasil yang menyesatkan. Dari permasalahan tersebut terciptalah suatu metode yang mengukur performa suatu perusahaan denggan memperimbangkan aspek aspek,seperti keuangan atau finansial, pelanggan, proses bisnis internal serta proses blajar dan berkembang yang metode ini dinamakan balanced scorecard Kalender \& Vayvay, (2016).

Pertama kali balanced scorecard dimulai dan diperkenalkan pada tahun 1990-an di USA oleh David P.Norton dan Robert S. Kaplan melalui suatu riset tentang "Pengukuran Kinerja dalam Organisasi Masa Depan". Balanced scorecard merupakan suatu istilah yang terdiri dari balanced (berimbang) dan scorcard (kartu skor). Kata balanced (berimbang) adalah suatu kinerja yang diukur secara seimbang baik dari sisi keuangan atau finansal maupun non keuangan, yang mencangkup jangka panjang atau jangka pendek serta melibatkan bagian internal dan eksternal. Sedangkan scorecard (kartu skor) merupakan suatu kartu yang dapat digunakan untuk mengukur performa dengan memperhatikan keseimbangan antara sisi keuangan maupun non keuangan. Konsep balanced 
scorecard yang diperkenalkan oleh David P.Norton dan Robert S. Kaplan adalah metode pengukuran kinerja dengan empat perspektif yaitu perspektif keuangan, perspektif pelanggan, perspektif proses bisnis internal serta perspektif pembelajaran dan pertumbuhan.

Dalam perjalanannya timbul gagasan dari pengurus Kelompok Tani Ternak Kartika Kencana untuk mendirikan sebuah koperasi, agar dapat berkontribusi lebih banyak lagi dalam roda perekonomian mikroyang diharapkan dapat ikut berperan dalam percepatan pertumbuhan ekonomi nasional dan terciptanya lapangan kerja baru. Pemilihan Koperasi Tani Duta Kartika Kencana sebagai objek penelitian karena fenomena yang terjadi koperasi ini yang tidak mengetahui dan belum melaksanakan balanced scorecard. Kemudian koperasi ini sudah bersertifikat resmi dari Kementerian Koperasi dan Usaha Kecil dan Menengah Republik Indonesia, serta sudah berstatus grade A yaitu koperasi telah melaporkan hasil RAT 3 Tahun buku terakhir secara berturut-turut. Selain itu, selama ini Koptan Duta Kartika Kencana untuk menilai kinerjanya hanya menggunakan rasio keuangan seperti rasio likuid tas, rasio solvabilitas, rasio ROE dan ROI. Dalam hal ini Koptan Duta Kartika Kencana perlu menambahkan penilaian kinerja dari balanced scorecard yang dimana ditambahkan perspektif pelangan, perspektif proses bisnis internal serta perspektif pertumbuhan dan pembelajaran. Tujuan dilakukan penambahan ini adalah unuk mengembangkan struktur tata kerja organisasi yang lebih responsif dan inovatif guna memberikan pelayanan yang berkualitas.

Dari latar belakang dan uraian, keterkaitan pemelihan Koperasi Tani Duta Kartika Kencana dengan fenomena yang terjadi, yaitu karena koperasi sudah bersertifikat resmi dan sudah mencapai garde A dan belum menerapkan balanced scorecard selain itu, pengukuran kinerja dari Koptan Duta Kartika Kencana masih menggunakan pengukuran secara tradisional, hanya menilai kinerjanya dari sisi keuangan saja dan tidak memperhatikan sisi non keuangan. Maka dalam analisis ini saya memberikan judul "Analisis Pengukuran Kinerja Koperasi Tani Duta Kartika Kencana dengan Program Balanced Scoecard" (Studi Kasus di Koperasi Tani Duta Kartika Kencana, Banjar Dinas Bangah Desa Panji, Kecamatan Sukasada, Kabupaten Buleleng).

Stewardship Theory hampir sama dengan teori keagenan (agency theory) yaitu hubungan dua pihak antara prinsipal (pemilik) dan steward (pelayan). Dalam koperasi prinsipal adalah anggota koperasi sedangkan steward adalah pengurus beserta manajer koperasi Lesáková \& Dubcová, (2016). Stewardship theory memiliki akar sosiologi dan psikologi yang didesain untuk menjelaskan situasi dimana manajer sebagai steward dan bertindak sesuai kepentingan pemilik Davis, Schoorman, \& Donaldson, (2018). Teori stewardship manajer serta pengurus akan berperilaku sesuai kepentingan bersama. Ketika keinginan steward tidak sama dengan keinginan prinsipal, steward akan berusaha untuk bekerja sama daripada harus menentang keinginan prinsipal (pemilik). Steward percaya bahwa dengan bekerja memajukan perusahaan maka kebutuhan personal akan terpenuhi. Oleh karena itu, seorang steward termotivasi untuk memaksimalkan kinerja organisasi, sehingga dapat memuaskan kepentingan prinsipal (pemilik) Quezada, Reinao, Palominos, \& Oddershede, (2019). 


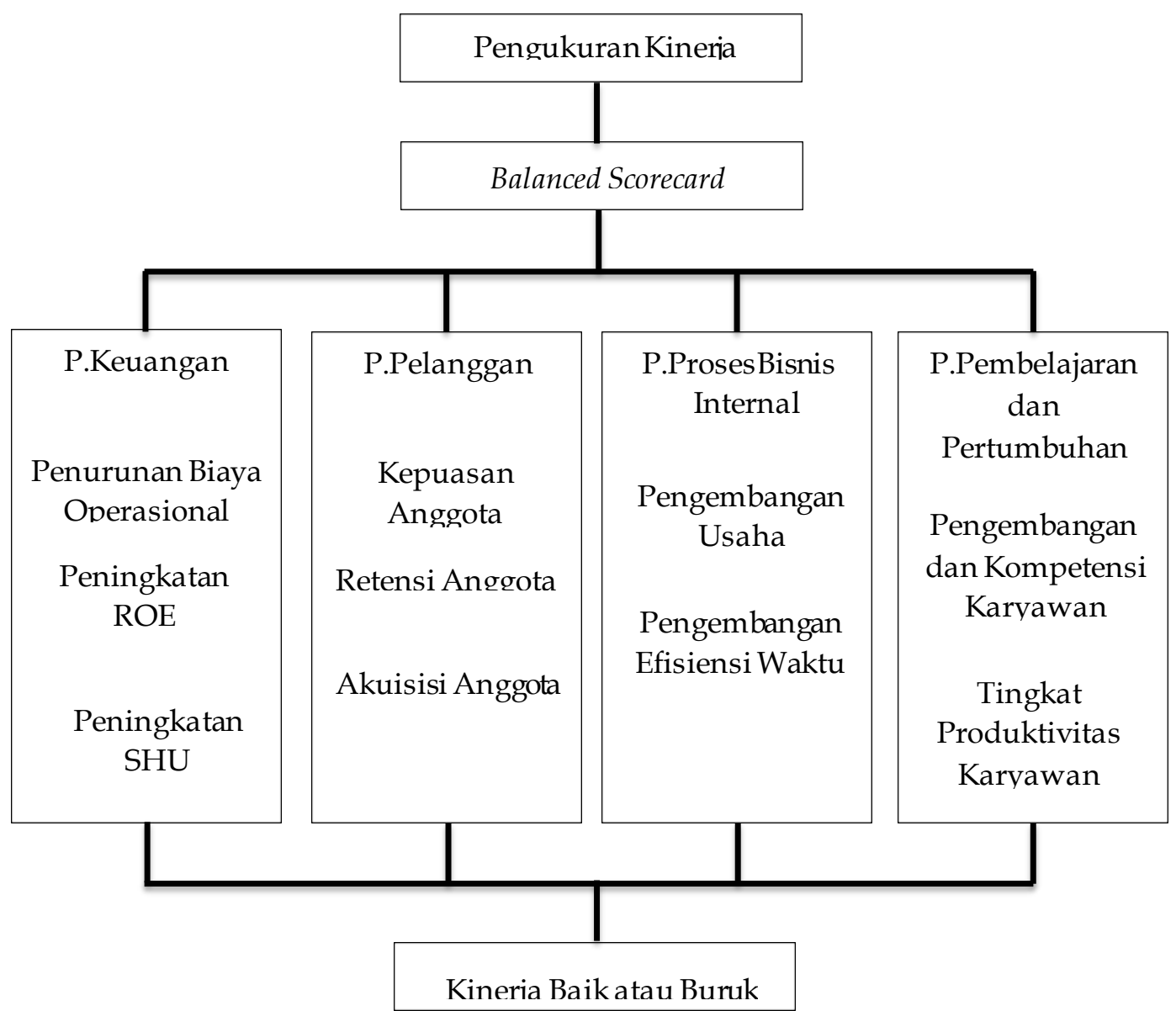

Gambar 1. Model Peneltian

\section{METODE PENELITIAN}

Pendekatan yang dilakukan dalam penelitian ini adalah pendekatan yang berbentuk deskriptif-komparatif dikarenakan penelitian ini sendiri bertujuan untuk menganalisis pengaruh dari variable perspektif pelanggan, perspektif keuangan, perspektif proses bisnis internal serta perspektif pembelajaran dan perbandingan antara target dengan realisasi program kerja Koperasi Tani Duta Kartika Kencana. Lokasi penelitian ini dilakukan di Koperasi Tani Duta Kartika Kencana, Banjar Dinas Bangah Desa Panji, Kecamatan Sukasada, Kabupaten bueleng. Variabel yang digunakan dalam proses penelitian, yakni Variabel independen (bebas), Perspektif Pelanggan (X1), Perspektif Keuangan (X2), Perspektif Proses Bisnis Internal (X3), serta perspektif pembelajaran dan pertumbuhan (X4). Variabel dependen (terikat), yaitu Kinerja Koperasi Tani Duta Kartika Kencana (Y).

Sumber data utama dalam penelitian deskriptif-komparatif adalah katakata dan tindakan, selebihnya adalah data tambahan seperti dokumen dan lainlain, menurut Paper, Guzman, Oktarina, \& Sugiyono, (2018). Menurut Siregar, (2015), "Cara jitu pengumpulan data dalam penelitian deskriptif-komparatif dikelompokan menjadi dua cara yakni, metode interaktif dan metode non 
interktif. Metode interaktif adalah metode yang digunakan dalam penelitian, metode interaktif meliputi wawancara (interview), observasi serta dokumentasi untuk mengumpulkan data pimer yang berhubungan dengan objek penelitian berhubungan dengan objek penelitian. Dalam penelitian ini peneliti menggunakan wawancara yang tidak terstruktur dan hanya memuat pertanyaan secara garis besar saja dan bergantung pada keadaan atau subjek. Percakapan yang dilakukan oleh dua pihak yaitu pewawancara (interviewer). Orang yang mengajukan pertanyaan dan yang diwawancarai (interviewee). Begitu pula orang yang menjawab pertanyaan dari pewawancara, wawancara ini dilakukan dengan maksud tertentu pewawancara, menurut Paper et al., (2018).

Dalam penelitian ini teknik analisis data yang digunakan oleh peneliti adalah pendekatan deskriptif-komparatif dengan menggunakan balanced scorecard untuk menilai pengukuran kinerja Koperasi Tani Duta Kartika Kencana. Dengan menggunakan dua variabel yaitu, variabel independen (bebas) dan variabel dependen (terikat). Variabel independen terdiri atas perspektif pelanggan (X1), perspektif keuangan $(X 2)$, perspektif proses binis internal (X3), serta perspektif pembelajaran dan pertumbuhan $(X 4)$. Sedangkan variabel dependen adalah kinerja Koperasi Tani Duta Kartika Kencana (Y).

Dalam melakukan pengukuran penelitian menggunakan beberapa persamaan sebagai berikut. Retensi anggota merupakan kemampan koperasi untuk mempertahankan hubungan antar anggotanya. Diukur dengan membandingkan anggota aktif dan anggota yang non aktif. Semakin besar retensi anggota, maka koperasi dianggap mampu mempertahankan anggotanya Shukri \& Ramli, (2015). Akusisi anggota (pelanggan), merupakan kemampuan koperasi untuk memperoleh anggota baru. Kepuasan anggota, merupakan kemampuan koperasi dalam memenuhi kebutuhan anggota dan kepuasa anggota terkait dengan pelayanan yang diberikan, sehingga dalam penelitian ini kepuasan anggota merupakan kepuasan yang dirasakan anggota terhadap seluruh kegiatan yang dilakukan koperasi, hal tersebut merupakan nilai koperasi Astuti, (2012).

Selain itu, kinerja perspektif keuangan dalam penelitian ini diukur menggunakan rasio Return On Equity (ROE). Rata rataSisa Hasil Usaha (SHU) dan Rasio Efisiensi Biaya (Rasio BOPO). Dalam penelitian kinerja perspektif proses bisnis internal menggunakan tingkat perkembangan jenis usaha (produk barang/jasa) Tsai et al., (2017). Manufacturing cycle efficiency (MCE), merupakan ukuran yang menunjukan persentase value added activities dalam suatu aktivitas yang digunakan oleh seberapa besar non value added activities dikurangi dan dieliminasi dari proses pembuatan produk, dalam proses pembuatan produk diperlukan cycle time yang merupakan keseluruhan waktu yang diperlukan untuk mengolah bahan baku menjadi produk jadi Tubis \& Werbińska, (2017).

Tingkat produktivitas karyawan dan kinerja perspektif pembelajaran dan pertumbuhan dalam penelitian ini diukur menggunakan produktivitas karyawan untuk tahun 2019. Terakhir adalah mengguakan kapabilitas karyawan. Pihak perusahaan harus mengikut sertakan karyawan yang bersangkutan pada seminarseminar atau pelatihan yang diadakan oleh Koperasi Tani Duta Kartika Kencana maupun pihak independen demi meningatkan kapabilitas karyawan.

\section{HASIL DAN PEMBAHASAN}


Koperasi Tani Duta Kartika Kencana didirikan di Buleleng pada tanggal 17 Juni 2008 dan telah terdaftar di Kanwil Koperasi Kabupaten Buleleng dengan Nomor Badan Hukum Pendirian 33/ BH/ XXVII. 3/VI/ 2008. Koperasi Tani Duta Kartika Kencana berada di alamat jalan Kibarak Panji Sakti Banjar Dinas Bangah, Kelurahan/Desa Panji, Kecamatan Sukasada, Kabupaten Bueleng, Bali. Koperasi Tani Duta Kartika Kencana memiliki bentuk koperasi primer Kabupaten/Kota, dengan jenis koperasi produsen. Koperasi Tani Duta Kartika Kencana merupakan kelompok koperasi pertanian, dengan sektor usaha pertanian, kehutaan dan perikanan. Adapundata pengurus, data kelembagaan dan data lainnya pada Koperasi Tani Duta Kartika Kencana adalah sebagai berikut.

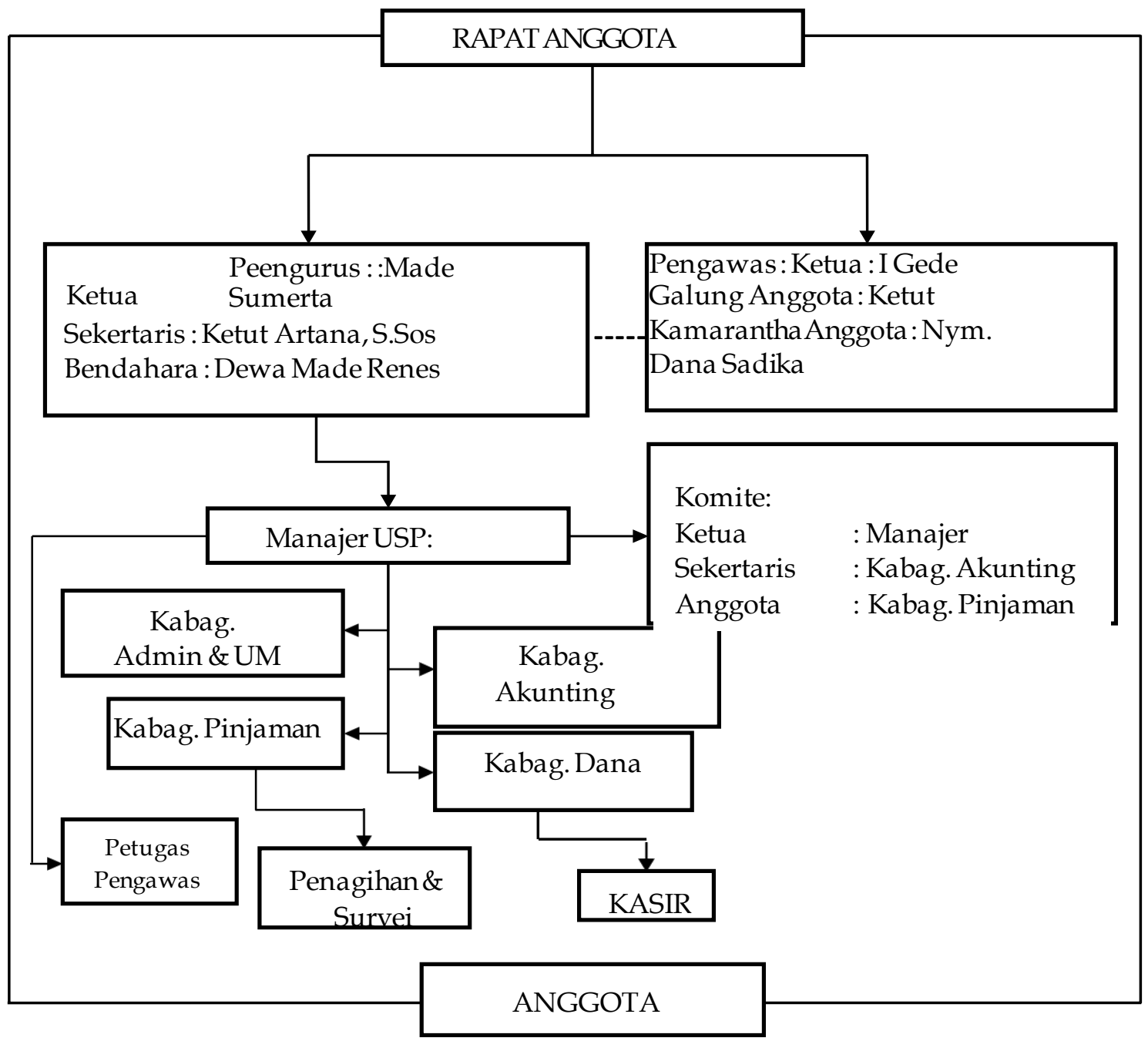

Gambar 2. Struktur Organisasi Koperasi Tani Duta Kartika Kencana

Program Kerja Koperasi Tani Duta Kartika Kencana Tahun Buku 2019. Koptan Duta Kartika Kencana dalam menyusun program kerja untuk tahun 2019 sebagai berikut. Bidang umum, memberikan bingkisan kepada anggota berupa kalender dan pembagian SHU, membuat peraturan-peraturan khusus, merevisi standar operasional dan manajemen serta standar operasional prosedur. Bidang organisasi dan kelembagaan, mengerjakan buku-buku organisasi koperasi sesuai fungsinya, meningkatkan SDM pengurus, pengawas, karyawan dan anggota, 
meningkatkan jumlah anggota sekurang-kurangnya 20 orang, melaksanakan rapat rutin usaha dan evaluasi bersama pengawas, pengurus dan pengelola koperasi, melaksanakan Rapat Anggota Rencana Kerja dan Rencana Anggaran Pendapatan dan Belanja Koperasi serta Rapat Anggota Tahunan sesuai ketentuan Anggaran Dasar secara tepat dan konsisten.

Temuan study yang dihubungkan dengan kajian teori, berdasarkan data yang ada terdapat kondisi yang mendukng melakukannya penerapan balanced scorecard sebagai sistem dari pengukuran kerja pada Koptan Duta Kartika Kencana. Kondisi tersebut merupakan koperasi yang sudah memilki visi, misi yang jelas dan mudah dipahami sehingga dapat dituangkan dalam konsep-konsep strategi yang jelas. Analisis yang dilakukan berdasarkan data yang sudah terkumpul dan terjemahkan visi, misi dan strategi ke dalam balanced scorecard Abdullah, Umair, \& Naeem, (2013).

Tabel 1. Retensi anggota pada Koperasi Tani Duta Kartika Kencana pada tahun 2019

\begin{tabular}{cccc}
\hline $\begin{array}{c}\text { Tahun } \\
2019\end{array}$ & Jumlah Anggota Aktif & Jumlah Anggota Keluar & $\begin{array}{c}\text { Retensi } \\
\text { Anggota }\end{array}$ \\
\hline Target & 755 & 20 & $97,3 \%$ \\
Realisasi & 860 & 11 & $98,7 \%$ \\
\hline
\end{tabular}

Sumber: Data Penelitian, 2021

Tabel 1, menunjukkan bahwa target retensi anggota Koperasi Tani Duta Kartika Kencana pada tahun 2019 sebesar 97,3\% dan pada tahun 2019 mencapai realisasi sebesar 98,7\%. Hal ini menunjukkan bahwa retensi anggota Koperasi Tani Duta Kartika Kencana pada tahun 2019 melebihi target yang ditentukan namun tidak signifikan. Realisasi sudah memenuhi target yang diingikan koperasi, beberapa anggota keluar diakibatkan karena adanya anggota berhenti atau meniggal dunia dan adanya anggota karyawan yang masa kontraknya sudah habis, sehingga dapat dinilai retensi anggota pada Koperasi Tani Duta Kartika Kencana "cukup baik".

Tabel 2. Akuisisi anggota pada Koperasi Tani Duta Kartika Kencana pada tahun 2019

\begin{tabular}{cccc}
\hline $\begin{array}{c}\text { Tahun } \\
2019\end{array}$ & Jumlah Anggota Baru & $\begin{array}{c}\text { Jumlah Anggota } \\
\text { Tahun Lalu }\end{array}$ & $\begin{array}{c}\text { Presentase } \\
\text { Akuisisi }\end{array}$ \\
\hline Target & 232 & 860 & $26,98 \%$ \\
Realisasi & 166 & 976 & $17,01 \%$ \\
\hline
\end{tabular}

Sumber: Data Penelitian, 2021

Tabel 2, menunjukkan bahwa target akuisisi anggota Koperasi Tani Duta Kartika Kencana pada tahun 2019 sebesar 26,98\% dan realisasi sebesar 17,01\%. Hal ini menunjukkan bahwa realisasi persentase akuisisi anggota Koperasi Tani Duta Kartika Kencana lebih rendah dibandingkan target yang telah ditentukan. Tidak tercapainya persentase akuisisi jumlah anggota tersebut diakibatkan karena adanya anggota yang berhenti dan adanya anggota karyawan yang masa kontraknya sudah habis, sehingga akuisisi anggota pada Koperasi Tani Duta Kartika Kencana dinilai "kurang baik". 
KUSUMA, I. G. C., \& SURYANAWA, I. K.

Tabel 3. Tingkat Indeks Kepuasan Pelanggan/Anggota Pada Koperasi Tani Duta Kartika Kencana

\begin{tabular}{|c|c|c|c|c|c|c|}
\hline Pernyataan & $\begin{array}{l}\text { Bobot \% } \\
\text { (I) }\end{array}$ & $\begin{array}{l}\text { Skor } \\
\text { Nyata } \\
\text { Rata- } \\
\text { Rata } \\
(P)\end{array}$ & $\begin{array}{l}\text { Skor } \\
\text { Arapan } \\
\text { Rata- } \\
\text { Rata } \\
\text { (E) }\end{array}$ & $\begin{array}{l}\text { Selisi } \\
\text { (E) }\end{array}$ & $\begin{array}{l}\text { IKK } \\
\text { Nyata } \\
I^{*}(P-E)\end{array}$ & Kriteria \\
\hline Mempunyai ruang & 10,06 & 3,58 & 5 & 1,42 & 14,28 & Puas \\
\hline $\begin{array}{l}\text { tunggu yang } \\
\text { nyaman }\end{array}$ & 13,03 & 4,64 & 5 & 0,36 & 4,69 & $\begin{array}{l}\text { Sangat } \\
\text { Puas }\end{array}$ \\
\hline Jumlah tempat & 13,09 & 4,66 & 5 & & 4,45 & Sangat \\
\hline duduk memadai & $\begin{array}{l}10,45 \\
10,17\end{array}$ & $\begin{array}{c}3,72 \\
3,62\end{array}$ & $\begin{array}{c}5 \\
5\end{array}$ & 0,34 & $\begin{array}{l}13,38 \\
14,03\end{array}$ & $\begin{array}{l}\text { Puas } \\
\text { Puas }\end{array}$ \\
\hline $\begin{array}{l}\text { Mempunyai } \\
\text { pendingin ruangan }\end{array}$ & $\begin{array}{l}12,70 \\
10,34\end{array}$ & $\begin{array}{l}4,52 \\
3,68\end{array}$ & $\begin{array}{l}5 \\
5\end{array}$ & $\begin{array}{l}1,28 \\
1,38 \\
0,48\end{array}$ & $\begin{array}{l}6,09 \\
13,64\end{array}$ & $\begin{array}{l}\text { Puas } \\
\text { Sangat } \\
\text { Puas }\end{array}$ \\
\hline $\begin{array}{l}\text { Media hiburan dan } \\
\text { informasi tersedia } \\
\text { di ruang tunggu }\end{array}$ & 10,45 & 3,72 & 5 & 1,32 & 13,38 & $\begin{array}{l}\text { Puas } \\
\text { Puas }\end{array}$ \\
\hline Toilet yang bersih & 9,72 & 3,46 & 55 & & 14,97 & \\
\hline $\begin{array}{l}\text { Tempatparkir } \\
\text { yangaman } \\
\text { SHUyang }\end{array}$ & 100 & 35,60 & & 1,28 & 98,91 & $\begin{array}{l}\text { Puas } \\
\text { Puas }\end{array}$ \\
\hline $\begin{array}{l}\text { dibagikan kepada } \\
\text { anggota sesuai } \\
\text { dengan kontribusi } \\
\text { anggota } \\
\text { SHUyang } \\
\text { dibagikan secara } \\
\text { tidaklangsung } \\
\text { meningkatkan } \\
\text { pendapatan } \\
\text { anggota } \\
\text { Penyelenggaraan } \\
\text { RAT tepatwaktu } \\
\text { Total } \\
\end{array}$ & & & & $\begin{array}{l}1,54 \\
9,40\end{array}$ & & \\
\hline \multicolumn{7}{|c|}{$\begin{array}{l}\text { Sumber: Data Penelitian, } 2021 \\
\quad \text { Skor harapan rata-rata pada indeks kepuasan pelanggan (IKP) ini memiliki } \\
\text { nilai tertinggi (maksimal) } 45 \text { dan terendah (minimal) 9, sehingga dapat disusun } \\
\text { kriteria pengukuran sebagai berikut. } \\
\text { Tabel 4. Rentang Skor dan Kriteria Indeks Kepuasan Pelanggan }\end{array}$} \\
\hline Nilai Skor & \multicolumn{6}{|c|}{ Kriteria } \\
\hline $\begin{array}{c}>16,20-23,40 \\
>23,40-30,6 \\
>30,6-37,8 \\
>37,8-45\end{array}$ & \multicolumn{6}{|c|}{$\begin{array}{l}\text { Sangat Tidak Baik/Sangat } \\
\text { Rendah } \\
\text { Tidak Baik/Rendah } \\
\text { Cukup/Sedang } \\
\text { Baik/Tinggi } \\
\text { Sangat Baik/Sangat Tinggi }\end{array}$} \\
\hline
\end{tabular}

Sumber: Data Penelitian, 2021 
Indeks Kepuasan Pelanggan yang diukur dengan 9 item pernyataan dengan bantuan skala likert 5 poin memiliki skor rata-rata nyata sebesar 35,60, yaitu berada pada rentang kriteria 30,6-37,8. Hal ini berarti pelanggan/anggota cenderung memiliki rasa kepuasan yang tinggi. Nilai rata-rata terendah Indeks Kepuasan Pelanggan terdapat pada pernyataan "toilet yang bersih" dengan nilai rata-rata sebesar 3,62. Hasil tersebut menunjukkan bahwa pelanggan/anggota merasa bahwa Koperasi Tani Duta Kartika Kencana kurang memiliki toilet yang bersih.

Terdapat rata rata kepuasan pelanggan berdasarkan hasil formulasi dari hasil indeks adalah sebesar 98,91 dengan kriteria penilaian puas. Hasil ini mengatakan bahwa para pelanggan merasa puas dengan kualitas yang diberikan oleh koperasi Tani Duta Kartika Kencana, sehingga dinilai "Baik".

Tabel 5. Rentang Skor dan Kriteria Indeks Kepuasan Pelanggan

\begin{tabular}{cccc}
\hline $\begin{array}{c}\text { Tahun } \\
2019\end{array}$ & $\begin{array}{c}\text { Sisa Hasil Usaha } \\
\text { (SHU) Setelah Pajak }\end{array}$ & $\begin{array}{c}\text { Kekayaan } \\
\text { Bersih }\end{array}$ & ROE \\
\hline Target & $105,387,869$ & $1,378,119,259$ & $7.64 \%$ \\
Realisasi & $106,932,258$ & $1,721,738,929$ & $6,21 \%$ \\
\hline
\end{tabular}

Sumber: Data Penelitian, 2021

Tabel 5, menunjukkan bahwa target Return On Equity Koperasi Tani Duta Kartika Kencana pada tahun 2019 sebesar 7,64\%, kemudian realisasinya pada tahun 2019 mencapai 6,21\%. Hal tersebut menunjukkan bahwa realisasi Return On Equity Koperasi Tani Duta Kartika Kencana pada tahun 2019 leih rendah dibandingkan dengan target atau realisasi belum mencapai target yang diinginkan oleh koperasi. Return On Equity merupakan suatu rasio yang harus diperhatikan karena anggota koperasai sebagai penyimpan dana merupakan pihak sebagai investor sehingga manajemen koperasi harus bertanggung jawab dalam mengelolanya. Berdasarkan nilai realisasi ROE tahun2019, koperasi dinilai kurang baik dalam meningkatkan sisa hasil usaha.

Tabel 6. Rata-rata Sisa Hasil Usaha (SHU) pada Koperasi Tani Duta Kartika Kencana pada tahun 2019 (dalam rupiah)

\begin{tabular}{cccr}
\hline Tahun & $\begin{array}{c}\text { Sisa Hasil Usaha(SHU) } \\
\text { yang dibagikan }\end{array}$ & Jumlah Anggota & Rata-RataSHU \\
\hline Target & $105,387,869$ & 1.142 & $92.283,60$ \\
Realisasi & $106,932,258$ & 1.374 & $92.825,52$ \\
\hline
\end{tabular}

Sumber: Data Penelitian, 2021

Tabel 6, menunjukkan bahwa target rata-rata Sisa Hasil Usaha Koperasi Tani Duta Kartika Kencana pada tahun 2019 sebesar Rp92.283,60 dan pada tahun 2019 mencapai realisasi sebesar Rp77.825,52. Hal ini menunjukkan bahwa realisasi rata-rata SHU Koperasi Tani Duta Kartika Kencana pada tahun 2019 lebih rendah dibandingkan target yang telah ditentukan, sehingga Koperasi Tani Duta Kartika Kencana dinilai kurang mampu meningkatkan kesejahteraan anggotanya sebab belum mencapai target yang ditentukan atau dapat dikatakan "Kurang Baik". 
Tabel 7. Rasio Efisiensi Biaya (Rasio BOPO) pada Koperasi Tani Duta Kartika Kencana pada tahun 2019 (dalam rupiah)

\begin{tabular}{cccc}
\hline $\begin{array}{c}\text { Tahun } \\
2019\end{array}$ & $\begin{array}{c}\text { Total Biaya } \\
\text { Operasional }\end{array}$ & Pendapatan & BOPO \\
& & & \\
\hline Target & 2.671 .161 .698 & 2.778 .049 .567 & $96,15 \%$ \\
Realisasi & 3.138 .290 .680 & 3.350 .477 .243 & $93,67 \%$ \\
\hline
\end{tabular}

Sumber: Data Penelitian, 2021

Tabel 7. menunjukkan bahwa target rasio Efisiensi Biaya Koperasi Tani Duta Kartika Kencana pada tahun 2019 sebesar 96,15\% dan pada tahun 2019 mencapai realisasi BOPO sebesar 93,67\%. Hal ini menunjukkan bahwa persentase realisasi rasio Efisiensi Biaya Koperasi Tani Duta Kartika Kencana pada tahun 2019 lebih rendah dari target yang ditentukan. Nilai rasio BOPO sudah memenuhi target yang diinginkan karena realisasi dari rasio efisiensi biaya lebih rendah dibandingkan target selama periode tahun 2019 maka efisiensi biaya dikatakan sudah efisien atau sudah baik.

Tabel 8. Perbandingan Waktu Standar dan Waktu Realisasi Proses Permohonan Kredit pada Koperasi Tani Duta Kartika Kencana pada tahun 2019

\begin{tabular}{lll}
\hline \multicolumn{1}{c}{ Waktu Proses } & $\begin{array}{l}\text { Waktu } \\
\text { Standar } \\
\text { (menit) }\end{array}$ & $\begin{array}{c}\text { Waktu } \\
\text { Realisasi } \\
\text { (menit) }\end{array}$ \\
\hline $\begin{array}{l}\text { Waktu Mengis Formulir } \\
\begin{array}{l}\text { Waktu PembuatanSurat Perjanjian dan } \\
\text { Lain-Lain }\end{array}\end{array}$ & $\begin{array}{l}8 \\
\begin{array}{l}\text { Waktu Penandatanganan Dokumen } \\
\text { Perjanjian Waktu Pencairan Kredit dan }\end{array}\end{array}$ & 7 \\
$\begin{array}{l}\text { PembuatanKartu } \\
\text { Jumlah WaktuProses }\end{array}$ & 25 & 3 \\
& 50 & 19 \\
\hline
\end{tabular}

Sumber: Data Penelitian, 2021

Berdasarkan Tabel 8, maka manufacturing cycle efficiency (MCE) dapat dihitung sebagai berikut.

$$
M C E=37 \div 50=74 \%
$$

Waktu proses pengolahan simpanan menunjukan koperasi menggunakan $74 \%$ waktu digunakan untuk aktivitas nilai tambah dan MCE mendekati 100\%, artinya transaksi permohonan simpan telah berjalan efisien karena waktu realisasi lebih cepat daripada waktu standar. Jadi efisiensi proses pelayanan Koperasi Tani Duta Kartika Kencana dapat dikatakan sudah optimal atau baik.

Tabel 9. Tingkat Produktivitas Karyawan pada Koperasi Tani Duta Kartika Kencana pada tahun 2019 (dalam rupiah)

\begin{tabular}{ccc}
\hline Tahun & 2018 & 2019 \\
\hline Pedapatan & 2.778 .049 .567 & 3.350 .477 .243 \\
Jumlah Karyawan & 18 & 18 \\
Produktivitas Karyawan & 154.336 .087 & 186.137 .624 \\
Rasio Produktivitas & - & $20,6 \%$ \\
\hline
\end{tabular}

Sumber: Data Penelitian, 2021

Tabel 9, menunjukkan bahwa target produktivitas karyawan pada Koperasi Tani Duta Kartika Kencana selama periode tahun 2019 adalah sebesar 
Rp154.336.087,06 dan mencapai realisasi sebesar Rp186.137.624,61 dengan rasio produktivitas sebesar 20,6\%. Hal ini menunjukkan bahwa pertumbuhan realisasi persentase rasio aktiva produktif Koperasi Tani Duta Kartika Kencana pada tahun 2019 sudah memenuhi target yang diinginkan. Oleh karena tingkat pertumbuhan produktivitas karyawan dikatakan "baik".

Tabel 10. Rasio Karyawan yang Dilatih Pada Koperasi Tani Duta Kartika Kencana

\begin{tabular}{lll}
\hline \multicolumn{1}{c}{ Tahun 2019 } & Target & Realisasi \\
\hline Jumlah pelatihan & 2 & 4 \\
Jumlah karyawan & 18 & 18 \\
$\begin{array}{l}\text { Jumlah karyawanyang dilatih } \\
\text { Rasio karyawanyang ikut } \\
\text { pelatihan }\end{array}$ & $16,7 \%$ & 7 \\
\hline umber: Data Penelitian, 2021 & & $38,89 \%$ \\
\hline
\end{tabular}

Tabel 10. menunjukan bahwa jumlah karyawan yang mengikut pelatihan dari tahun ke tahun secara signifikan adanya peningkatan. Keikutsertaan karyawan dalam pelatihan maupun seminar merupakan proses peningkatan sumber daya manusia supaya dapat memberikan efek kemajuan bagi koperasi Tani Duta Kartika Kencana, tingkat pelatihan karyawan sudah dinilai "baik”.

Tabel 11. Ikhtisar Hasil Pengukuran Kinerja Koperasi Tani Duta Kartika Kencana dengan Balanced Scorecard

\begin{tabular}{cccc}
\hline Perspektif & Tahun 2019 & Kriteria & $\begin{array}{l}\text { Rating } \\
\text { Scale }\end{array}$ \\
\hline
\end{tabular}

Perspektif Keuangan Return On Equity 7,64\% 6,21\% Kurang-1

(ROE)

Rata-rata Sisa Hasil Rp 92.283,60 Rp 77.825,52 Kurang -1

Usaha (SHU)

Efisiensi Biaya 96,15\% 93,67\% Efisien 1

(Rasio BOPO)

Kinerja Perspektif KepuasanPelanggan/Anggota

Retensi Anggota 97,3\% 98,7\% Cukup 0

Persentase Akuisisi 26,98\% 17,01\% Kurang -1

Indeks Kepuasan 98,91 Baik1

Pelanggan(IKP)

Kinerja Perspektif Proses Bisnis Internal

MCE Proses 74\% Baik1

Permohonan Kredit

Kinerja Perspektif KepuasanPelanggan/Anggota

Tingkat produktivitas 10\% 20,6\% Baik1 karyawan

Kapabilitas 16,67\% 38,89\% Baik1

Karyawan

Total 2

Rata-Rata Skor 0,2

Sumber: Data Penelitian, 2021

Tabel 11. menunjukan bahwa kinerja dalam perspektif keuangan ROE (Return On Equity) memliki rata rata kurang baik atau kurang optimal, sehingga diberi skor -1 (kurang baik), begitu juga dengan rata-rata SHU diberi skor -1 
(kurang baik). Sedangkan Efisiensi Biaya (Rasio BOPO) diberi skor 1 (sudah efisien atau baik). Untuk perspektif pelanggan menunjukkan bahwa tingkat retensi anggota sudah memenuhi target tidak terlalu signifikan diberi skor 0 (cukup baik) dan persentase akuisisi belum mencapai target yang diinginkan maka skornya -1 (kurang baik). Pada perspektif bisnis internal, nilai dari MCE proses permohonan kredit diberi skor 1 (baik), sedangkan indeks kepuasan pelanggan skor 1 (baik). Kemudian yang dilihat dari sudut pandang pertumbuhan dan pembelajaran dari kegiatan produksi dan indeks kepuasan karyawan menunjukkan skor 1 (baik). Diketahui total bobot skor, yaitu sebesar 3 poin dari total boot standar. Jadi skor rata-ratanya adalah $2 / 9=0,2$. Tahap selanjutnya adalah prose pembuatan skala untuk menilai total poin sehingga dapat kesimplan kinerja persuhaan dapat dibilang "kurang", "cukup", atau "baik".

\section{SIMPULAN}

Program kerja Koperasi Tani Duta Kartika Kencana mengharuskan kinerja diukur mengguakan balanced scorecard, karena banyak target baik dari aspek keuangan maupun non keuangan yang ingin dicapai. Indikator yang digunakan koperasi selama ini hanya untuk mengukur aspek keuangan saja, indikator atau alat ukur yang digunakan koperasi tidak sesuai dengan kinerja yang ingin dicapai koperasi itu sendiri. Peneliti mengusulkan balanced scorecard digunakan untuk mengukur kinerja baik dari aspek keuangan dan non keuangan. Balanced scorecard dapat mengelompokan target program kerja Koperasi Tani Duta Kartika Kencana dalam beberapa indikator-indikator yang sudah dipaparkan pada hasil penelitian. Teori stewardship merupakan hubungan antara dua pihak prinsipal (anggota koperasi) dan steward (manajer dan pengurus koperasi), steward berperilaku sesuai dengan kepentingan prinsipal. Dari hasil penelitian, pihak steward sudah mengerahkan segala kemampuan untuk merealisasikan keinginan dari pihak prinsipal, meskipun belum maksimal. Jadi implikasi dalam penelitian sudah mendukung teori stewardship dan diharapkan implikasi penelitian akan membantu koperasi dalam hal pemilihan indikator-indikator untuk mengukur aspek keuangan maupun non keuangan bagi kegiatan operasional koperasi.

Sedikit saran untuk pengurus atau manajemen koperasi agar selalu memberikan sosialisasi atau pelatihan mengenai penjelasan penjelasan tentang produk baru maupun produk yang sudah ada di koperasi sehingga mereka mendapatkan informasi-informasi yang baru agar bisa menjelaskan secara detail kepada pelanggan agar para pelanggan mengetahui hal hal baru yang berguna bagi produk tersebt sehingga membuat memunculkan minat, ketertarikan serta loyalitas dalam menggunakan barang dan jasa tersebut. Jika ingin melakukan penelitian yang sama selanjutnya menggunakan sampel koperasi lainya agar membuat penelitian menjadi lebih luas.

\section{REFERENSI}

Abdullah, I., Umair, T., \& Naeem, B. (2013). Developments on Balanced scorecard: A Historical Review. World Applied Sciences Journal, 21(1), 134-141. https:/ / doi.org/10.5829/idosi.wasj.2013.21.1.2314

Astuti, S. R. (2012). Pengaruh Modal Sosial Dimensi Relasional, Modal Sosial Dimensi Struktural, Dan Motivasi Terhadap Kinerja In-Role Dan Ex-Role 
Karyawan "Koperasi Karyawan Angkasa Pura I (Kokapura Avia) Ground Handling." Jurnal Manajemen, 2(1), 49-58.

Daulay, R., Muhyarsyah, \& Astuty, W. (2019). The Utilization Of Management Differential Accounting In Decision Making Regarding Fixed Asset Investment At Pdam Tirtanadi, North Sumatera Province. The 1st MultiDiscipinary International Conference University Of Asahan, 671-679.

Davis, J. H., Schoorman, F. D., \& Donaldson, L. (2018). Toward A Stewardship Theory Of Management. Business Ethics And Strategy, Volumes I and II, 22(1), 473-500. https://doi.org/10.4324/9781315261102-29

Ekmekçi, Y. A. D. (2014). Implementing Of Balanced scorecard: Sample Of Turkish Republic Ministry Of Youth And Sport. Procedia - Social And Behavioral Sciences, 150, 754-761. https:/ /doi.org/10.1016/j.sbspro.2014.09.046

Fatima, T., \& Elbanna, S. (2020). Balanced scorecard In The Hospitality And Tourism Industry: Past, Present And Future. International Journal Of Hospitality Management, $\quad$ 91(February), 102656. https:/ / doi.org/10.1016/j.ijhm.2020.102656

Herawati, N. R., Isnandi, A. V., \& Sari, Y. E. (2018). Pengukuran Kinerja Koperasi Berbasis Balanced scorecard. Ekonika: Jurnal Ekonomi Universitas Kadiri, 3(1), 63. https:/ / doi.org/10.30737/ekonika.v3i1.97

Horngren, C. T., \& George, F. (1992). Akuntansi Biaya: Suatu Pendekatan Manajerial. Edisi 6 Jilid 1.

Indranatha, I. G. N. A. L., \& Suryanawa, I. K. (2013). Pengukuran Kinerja Berbasis Balanced scorecard Pada Koperasi Serba Usaha Kuta Mimba. E-Jurnal Akuntansi Universitas Udayanakuntansi Universitas Udayana, 4(3), 451-471. Retrieved from https:/ /ojs.unud.ac.id/index.php/ Akuntansi/article/view/6328

Kádárová, J., Durkáčová, M., \& Kalafusová, L. (2014). Balanced scorecard As An Issue Taught In The Field Of Industrial Engineering. Procedia - Social and Behavioral Sciences, 143, 174-179. https:/ / doi.org/10.1016/j.sbspro.2014.07.382

Kalender, Z. T., \& Vayvay, Ö. (2016). The Fifth Pillar Of The Balanced scorecard: Sustainability. Procedia - Social and Behavioral Sciences, 235(October), 76-83. https:// doi.org/10.1016/j.sbspro.2016.11.027

Karabulut, A. T. (2015). Effects Of Innovation Types On Performance Of Manufacturing Firms In Turkey. Procedia - Social And Behavioral Sciences, 195, 1355-1364. https:/ /doi.org/10.1016/j.sbspro.2015.06.322

Kruger, S. D., Simionato, A., Zanella, C., \& Petri, S. M. (2018). Balanced scorecard: A Proposal For Strategic Management Of A Rual Cooperative Credit. Rev. Adm. UFSM, 11(2), 471-488. https:// doi.org/10.5902/19834659

Lesáková, Ĺ., \& Dubcová, K. (2016). Knowledge And Use Of The Balanced scorecard Method In The Businesses In The Slovak Republic. Procedia - Social And Behavioral Sciences, 230(May), 39-48. https:/ / doi.org/10.1016/j.sbspro.2016.09.006

Paper, W., Guzman, K. C., Oktarina, N., \& Sugiyono. (2018). Metodologi Penelitian Pendidikan Pendekatan Kuantitatif, Kualitatif dan R\&D, (Bandung: Alfabeta, 2008). Economic Education Analysis Joumal, 7(1), 335-336.

Pujiono, D. S., Sukarno, H., \& Puspitasari, N. (2016). Pengaruh Daerh Sistem Pengendalian Intern Terhadap Pengelolaan Keuangan Daerah Serta Kinerja 
Pemerintah Daerah (Studi di Provinsi Maluku Utara). Jurnal Bisnis Dan Manajemen, 10(1), 68-81.

Pura, R. A. H. dan R. (2020). Pengaruh Aspek Pengukuran Kinerja Dalam Balanced scorecard Terhadap Daya Saing Perusahaan Pdam Kota Makassar. Jurnal Akuntansi Dan Ekonomi, 6(1),67-74. https:/ /doi.org/10.29407/jae.v6i1.14204

Quezada, L. E., Reinao, E. A., Palominos, P. I., \& Oddershede, A. M. (2019). Measuring Performance Using SWOT Analysis And Balanced scorecard. Procedia Manufacturing, 39(2019), 786-793. https:/ / doi.org/10.1016/j.promfg.2020.01.430

Rasmini, N. K., Supadmi, N. L., \& Sucandra, N. L. P. H. (2011). Penilaian Kinerja Badan Rumah Sakit Umum Tabanan Berdasarkan Balanced scorecard. Jurnal Ilmiah Akuntansi Dan Bisnis, 6(2).

Shukri, N. F. M., \& Ramli, A. (2015). Organizational Structure And Performances Of Responsible Malaysian Healthcare Providers: A Balanced scorecard Perspective. Procedia Economics And Finance, 28(April), 202-212. https:/ / doi.org/10.1016/s2212-5671(15)01101-6

Siregar, M. (2015). Upaya Meningkatkan Hasil Belajar Siswa Melalui Model Pembelajaran Komperatif Tife Stad Pada Konpensasi Dasar Mendeskrifsikan Hakikat Demokrasi Kelas VIII SMP Negeri 3 Montong Tahun Pelajaran 2014/2015. CIVITAS, 1(1), 12-22.

Sudibyo, B. (1997). Pengukuran Kinerja Perusahaan Dengan Balanced scorecard Bentuk Mekanisme Dan Prospek Aplikasinya Pada Bumn. Ekonomi Dan Bisnis Indonesia, 12(2). Retrieved from https:/ /jurnal.ugm.ac.id/jieb/article/view/ 40049

Tsai, J. M., Chien, H. H., Shih, S. C., Lee, S. C., Tsai, L. Y., \& Tsay, S. L. (2017). Using Balanced scorecard On Reducing Fall Incidents And Injuries Among Elderly Cancer Patients In A Medical Center In Taiwan. International Journal Of Gerontology, 11(4), 253-257. https://doi.org/10.1016/j.ijge.2016.05.012

Tubis, A., \& Werbińska, W. S. (2017). Balanced scorecard Use In Passenger Transport Companies Performing At Polish Market. Procedia Engineering, 187, 538-547. https:/ / doi.org/10.1016/j.proeng.2017.04.412

Wang, S. H., Chang, S. P., Williams, P., Koo, B., \& Qu, Y. R. (2015). Using Balanced scorecard For Sustainable Design-Centered Manufacturing. Procedia Manufacturing, 1, 181-192. https:// doi.org/10.1016/j.promfg.2015.09.084 